\title{
Is the relationship between innovation performance and knowledge management contingent on environmental dynamism and learning capability? Evidence from a turbulent market
}

\author{
Rifat Kamasak ${ }^{1} \cdot$ Meltem Yavuz ${ }^{2}$ Gultekin Altuntas ${ }^{2}$
}

Received: 16 September 2015/ Accepted: 9 February 2016/Published online: 19 February 2016

(C) The Author(s) 2016. This article is published with open access at Springerlink.com

\begin{abstract}
This study aims to explore the separate and combined effects of knowledge management capabilities, environmental dynamism and learning capability on innovation performance. To achieve this aim, a survey was carried out on a sample of 221 firms and a couple of hypotheses were tested. The findings showed that higher levels of environmental dynamism and learning capability made the positive linkage between knowledge management capabilities and innovation performance stronger. Based on the findings, it was suggested that whilst environmental dynamism may compel firms to assimilate and use new information better, create more new product configurations and move readily to new markets through their knowledge management capabilities, learning capability improves the understanding of organizational knowledge and helps the firm embed this knowledge into organizational processes. In this sense, environmental dynamism and learning capability moderate the relationship between knowledge management capabilities and innovation performance.
\end{abstract}

Keywords Environmental dynamism · Innovation · Knowledge management $\cdot$ Learning capability $\cdot$ Emerging markets $\cdot$ Regression analysis · Turkey

Rifat Kamasak

rkamasak@yeditepe.edu.tr

Meltem Yavuz

meltem.yavuz@istanbul.edu.tr

Gultekin Altuntas

altuntas@istanbul.edu.tr

1 Yeditepe University, Istanbul, Turkey

2 Istanbul University, Istanbul, Turkey 
JEL Classification $\quad$ L1 $\cdot$ M190

\section{Introduction}

Investigation of the factors that influence innovation performance has been a crucial academic and managerial concern since innovation has become essential for firms to retain their competitiveness and ensure long-term survival in dynamic global markets (Molina-Castillo and Munuera-Aleman 2009; Anderson et al. 2014). Scholars and practitioners in the field agreed that specific knowledge stock of a firm along with the skills that enable firms to manage their static knowledge resources effectively were the most important determinants of superior innovation performance (Grant 1996; Davenport and Prusak 2000; Tanriverdi 2005; Hegde and Shapira 2007; Yayavaram and Chen 2015).

The abilities which enable a firm to manage knowledge resources across its business units effectively through a series of processes including creation, transfer, integration and application were termed "knowledge management capabilities" (Gold et al. 2001; Tanriverdi 2005). Previous research (Darroch 2005; Palacios et al. 2009; Phelps et al. 2012; Wu and Chen 2014) found that knowledge management capabilities (KMC) were highly associated with innovation performance. Besides, the facilitating role of KMC on organizational innovativeness was meta-analytically confirmed (Van Wijk et al. 2008).

Despite the insightful findings of previous research that tested the direct influence of KMC on innovation performance, empirical studies examining the effects of contextual variables such as environmental dynamism (ED) on this relationship have been rare (Sirmon et al. 2011; Anderson et al. 2014). Additionally, as another contextual variable, learning capability (LC) has received considerable attention on the way of improving the creation and utilization of the important knowledge in firms over the past two decades. Numerous studies (Tsoukas and Mylonopoulos 2004; King 2009; Zhao et al. 2013) in the knowledge management literature indicate that LC mainly contributes firms by improving their KMC since a greater LC provides a better internal and external coordination and managerial commitment, creates a more effective teamwork and openness, and enables firms to adapt new knowledge easier (Jerez-Gomez et al. 2005; Spender 2008). In this sense, LC is a critical complementary to KMC and should be considered as an important moderator in the relationship between KMC and innovation performance (EasterbySmith and Lyles 2003; Wu and Chen 2014). Besides, the effects of LC and ED can be stronger on the KMC and innovation relationship especially in high turbulent environments where quick and thorough understanding of changes and adaptation of new knowledge is a must (Eisenhardt 1989; Schilke 2014).

However, only a few empirical studies (i.e., O'Connor 2008; Wei et al. 2014) have examined the combined effects of LC and ED on the link between KMC and innovation performance. The complex interactions of different contextual factors and mechanisms on the way of creating innovation performance still remain opaque in innovation research (Rosing et al. 2011; Anderson et al. 2014). Without a thorough analysis of these interactions which have a certain explanatory power, 
innovation performance-related issues in organizations cannot be understood (Sirmon et al. 2011; Helfat and Winter 2011). Firms operate in dynamic environments and they should dynamically reconfigure their resource portfolio to leverage their KMC for better innovation performance (Garg et al. 2003; Sirmon et al. 2007; Sirmon et al. 2011). Thus, the leverage and deployment of KMC leading to innovation performance may be affected by the nature of the external environment along with the capability of learning and ED and LC may have a moderating role on the relationship between $\mathrm{KMC}$ and innovation performance (Jansen et al. 2006, 2009; Wei et al. 2014; Schilke 2014).

Therefore, this study seeks to explore the separate and combined effects of KMC, ED and LC on innovation performance. The study contributes to the fields of knowledge management and innovation literature in several ways: first, based on the dynamic resource management view, this article extends previous knowledge and innovation research from a static view to a more dynamic view by exploring the combined effects of KMC, ED and LC in the same study. From this point of view, a more integrative model of $\mathrm{KMC}, \mathrm{ED}, \mathrm{LC}$ and innovation performance is offered.

Second, this research provides new evidence on the effects of KMC on innovation performance in an emerging market, Turkey, where fast information and knowledge integration along with application is crucial for firms to adapt to a dynamic environment. The vast majority of the empirical research on innovation and knowledge has been carried out in developed countries where rapid and discontinuous changes are uncommon but limited prior research (e.g., Hoskisson et al. 2000; Liu et al. 2013; Wang and Rafiq 2014) shows that emerging market firms which operate in turbulent business environments did not only have different priorities in their resource possessions but they also acquired different capabilities compared to developed country firms depending on dissimilar economic, political and social structures. The most striking difference in resource and capability possession between developed country and emerging market firms that was affected by environmental dynamism is that whilst developed country firms use organizational routines, emerging market firms highly utilize from the knowledge-based processes (Drnevic and Kriauciunas 2011; Liu et al. 2013; Ray et al. 2013). It is simply because, routines are the repetitive joint actions embedded in firms and mostly codified in manuals which regulate and standardize procedures, methods, tasks, decisions, solutions, and to some extent the way of doing business of the firms (Salvato and Rerup 2011; Dionysiou and Tsoukas 2013).

Namely, routines aim to offer standard procedures and solutions to the firms when they are faced with problems to minimize resource wastages (time, money, etc.) and increase organizational efficiency. Hence, many of the organizational routines may be very stable such as production procedures, new product development processes, quality and inventory management, pricing or recruitment (Becker 2004; Anand et al. 2012). The power, conflict and market-related problems in emerging markets may arise in mutating and unexpected ways and in these difficult times, emerging market firms may have to find creative and quick solutions (Ramamurti 2012). Because organizational routines are standard and stable in nature, they may restrict the strategic flexibility, modification and maneuvering capabilities of the firms. However, strategic flexibility which "allows firms to 
respond quickly to dynamic and unstable environmental changes by committing resources to new courses of action, and recognize and act promptly when it is time to halt or reverse existing resource commitments" (Liu et al. 2013: 82) is particularly important for the firms operating in emerging markets. In contrast to organizational routines, the IT-based skills and social software, customer relationship management (CRM) systems, enterprise resource planning (ERP), electronic data interchange (EDI), and supply chain management (SCM) systems as the components of KMC provide firms agility and enable them to respond hypercompetitive market demands quickly through innovative products and services (D’Aveni 1994; Ray et al. 2004; Ray et al. 2013).

Hence, in response to the recent calls (e.g., Tellis et al. 2009; Kamal 2011; Wei et al. 2014) that point out the necessity of more emerging market-specific theoretical and empirical inquiries into knowledge, learning and general streams of innovation, the study contributes to the performance implication of $\mathrm{KMC}$, in particular to the contextual efficacy of emerging market firms.

\section{Theory and hypotheses development}

\subsection{Knowledge management and innovation relationship}

Innovation emerges as a result of the combination of knowledge elements in organizations (Schumpeter 1934; Weitzman 1998). Similarly, Nonaka (1994) and Amabile (1996) consider knowledge as the key raw material for innovation. Many studies (Smith et al. 2005; Bell and Zaheer 2007; Van Wijk et al. 2008; Wu and Chen 2014) in innovation research have consistently indicated that the knowledge resources of a firm were strongly associated with innovation success. However, Easterby-Smith and Prieto (2008: 238) state that "it is important to distinguish knowledge resources from the process of trying to manage it". Although knowledge assets can be treated as unique and valuable resources on the way of sustaining competitive advantage (Barney 1991), knowledge itself is a static resource stock which needs to be transferred and spread throughout the organization to create value (Grant 1996, 1997; Spender, 1996; Teece et al. 1997; Teece 1998; Grant and BadenFuller 2004). In line with the dynamic capabilities (DC) perspective which posits that organizations should purposefully create, extend or modify its resource base to cope with ED (Teece et al. 1997; Helfat and Peteraf 2003), Spender (1996) focuses on the dynamic side of knowledge such as knowledge creating, processing and transferring rather than on knowledge per se as an economic asset. The author argues that competitive advantage is more likely to derive from firm-specific knowledge and stresses the importance of the conversion of static knowledge into a more dynamic nature (e.g., from declarative to procedural knowledge and; from tacit to explicit knowledge). With this premise, examination of the abilities of an organization in generating valuable knowledge through a series of activities has always created attention for the knowledge-based view (KBV) and DC scholars (Spender 1996; Grant 1997; Teece 1998; Droge et al. 2003; Lee and Choi 2003; Tanriverdi 2005; Tortoriello 2015). 
Knowledge can be managed through a series of coordinated processes that are creation, transfer, integration and application (Nonaka 1994; Alavi and Leidner 2001; Gold et al. 2001; Tanriverdi 2005). Whilst knowledge creation includes acquisition of knowledge from internal and external sources (such as employees, customers, suppliers and competitors) and conversion of knowledge into applicable formats along with the storage in organization's knowledge repository (Wu and Chen 2014), knowledge transfer refers to the distribution and sharing of knowledge throughout the organization at all levels from individuals to divisions (Alavi and Leidner 2001; Lee and Choi 2003).

Knowledge integration is the organization, restructuring and interpretation of existing knowledge through "directives, organizational routines, and self-contained task teams" (Alavi and Leidner 2001: 122) to establish a base into new meaningful knowledge and maximize knowledge synergy (Wu and Chen 2014). Knowledge application is the actual use of valuable and strategic knowledge on the way of developing organizational competencies and realizing organizational outcomes such as "changes in the behavior of recipients, new product developments, improvement in innovation and operational excellence, enhancement in external relationships, adjustments in strategic direction and changes in competitive conditions" (Wu and Chen 2014: 1145) which may sustain competitive advantage. These four knowledge processes complement and mutually support each other and "they enable the firm to create and exploit the cross-unit knowledge synergies, and to renew them as they depreciate and become obsolete" (Tanriverdi 2005: 314).

KMC can be operationalized via an appropriate combination of several human and technology initiatives (Tanriverdi 2005; Easterby-Smith and Prieto 2008; Bansemir et al. 2012). Whilst the technology side utilizes IT infrastructures, data warehouses, intranet, document management systems, collaborative platforms and virtual centers of expertise, call centers, enterprise databases (ERP), decision support systems and other technical and managerial procedures, "the human side focuses on the sense-making behaviors of individuals, on social relations and cultural factors when handling organizational knowledge" (Easterby-Smith and Prieto 2008: 239). Appropriate combination of KMC enables firms to find existing embedded organizational knowledge and create new knowledge, facilitate the transfer, share and transformation of this knowledge at all organizational levels as well as helping firms to develop competencies through various organizational outcomes (Zahra and George 2002; Joshi et al. 2010; Bansemir et al. 2012).

Several researchers (Zahra and George 2002; Darroch 2005; Tanriverdi 2005; Easterby-Smith and Prieto 2008; Palacios et al. 2009; Yayavaram and Chen 2015) state that creativity and innovation-related performance outcomes are highly associated with KMC. In her study, Darroch (2005) empirically confirmed that firms which could use KMC efficiently were more innovative. The study of Palacios et al. (2009) that was carried out in 222 from the Spanish biotechnology and telecommunications industries showed that KMC had a positive impact on innovation and entrepreneurship performance of the firms. Mitchell (2006) suggests that creating and applying new knowledge or revealing and reconfiguring already existing knowledge results in new products or services which in turn culminate in innovation success. 
As an example, Marks and Spencer (M\&S) which was a historically successful firm, suffered from decreasing profits and market share in 1990s (Ambrosini and Bowman 2009). The main weakness of the firm was a lack of understanding of its customers and local and global fashion and trends, and a lack of reaction to their shifting needs. The firm had a fad image of old-fashioned classical British brand. To overcome this problem, the firm established a new market intelligence system collecting and integrating knowledge inside and outside of the firm that improves the knowledge gathering capability of the firm significantly. New collaborative practices between $M \& S$ 's customers and suppliers that increase the understanding of customer needs were introduced. As a result, the firm offered its innovative product range which includes machine washable wool tailoring and suits for men, non-iron cotton clothing, non-polish shoes, and sensitive skin clothing for children. Twelve items of the product range were awarded "Millennium Product" status; this was the highest number of awards made to any single company in the UK (Sourced from the M\&S's website).

In more recent studies, Moos and Beimborn (2013), and Yayavaram and Chen (2015) have searched the relationship between KMC and innovation performance. The study of Moos and Beimborn (2013) which was conducted on German firms revealed that KMC which facilitated the identification, acquisition and assimilation of relevant knowledge from internal or external sources created a positive impact on innovation performance. Similarly, based on a longitudinal data set comprising all U.S. firms listed in Standard \& Poor's COMPUSTAT database from 1976 to 2004, Yayavaram and Chen (2015) studied the effects of KMC on innovation performance. The authors found that KMC had a positive effect on innovation performance because they enable the firms to change their knowledge base combinations and integrate new and existing knowledge domains leading to invention outcomes of greater value. Therefore, this study proposes that:

$\mathrm{H}_{1}$ : KMC will have a positive relationship with innovation performance.

\subsection{Moderating effect of environmental dynamism (ED)}

Environmental dynamism (ED) describes the rate of change, unpredictability, volatility and instability in external environment (Hoskisson et al. 2000; Jansen et al. 2009). Sirmon et al. (2007: 275) state that ED results to high amount of uncertainty that "produces deficits in the information needed to identify and understand cause and effects relationships". When environments are highly dynamic, uncertainty may inhibit an organization's ability to respond the need for change, to predict customer demands, to question the existing strategic direction, and to explore new alternatives (Levinthal and March 1993; González-Benito et al. 2012). However, a turbulent environment where external changes are non-linear and discontinuous can also be a great source of opportunity for firms to strengthen their existing capabilities and/or develop new ones which enable firms to overcome their organizational inertia and myopia of learning (Levinthal and March 1993; D'Aveni 1994; Ambrosini and Bowman 2009; Schilke 2014). In line with this, early literature (e.g., Lewin et al. 1999; Eisenhardt and Martin 2000) prescribes conceptually the high necessity of strong market intelligence, rapidly created knowledge and 
application of this knowledge to the product and market decisions to be able to address changes in dynamic environments.

Some theorists (e.g., Eisenhardt 1989; Eisenhardt and Martin 2000; Zahra et al. 2006; O'Connor 2008) suggest that high uncertainty environments compel firms to develop better KMC which promote creation of new, situation-specific knowledge and improve creative thinking that lead to superior innovation performance. If an environment is perceived to be dynamic, firms need to use existing knowledge repositories more effective and improve their KMC through real-time information, cross-functional networking, and intensive communication supported by IT skills to help link the nonlinear learning experiences to one another and to the innovation outcomes (Eisenhardt 1989; Ambrosini and Bowman 2009; Yayavaram and Chen 2015). For example, in Turkey where there is a high velocity in financial markets creating payment embarrassment for the customers, most of the banks developed inhouse knowledge management software which enabled customers and employees to have electronic brainstorming sessions by linking the web-portals and other social media tools. As a result, a number of innovative ideas such as credit cards offering customers to make their payments in monthly installments, unique dividend payment methods, gold participation accounts and hi-tech ATM machines that enable customers to withdraw and/or deposit gold bullions to their accounts were generated.

Obviously, in dynamic environments, resource possession priorities of firms may change and special capability deployment and leverage requirements of firms may increase (Cavusgil et al. 2007). Emerging market firms must deal with a high variety of market segments along with rapid and discursive consumer shifts that may emerge as a consequence of divergent income distribution and low education levels of consumers (Cavusgil et al. 2013). Prior research (e.g., Hoskisson et al. 2000; Jansen et al. 2006; Liu et al. 2013) shows that emerging market firms which operate in harsh business environments where high ED occurs have acquired different learning and knowledge management capabilities compared to developed country firms. The success of emerging market firms such as Tata of India, Lenovo and Huawei of China, Embraer of Brazil, and Lukoil of Russia did not only emanate from their low-cost advantages but also from their great skills of screening the market needs (e.g., when to change product ranges and/or accelerate product logistics) through their effective KMC (Ramamurti 2012; Cavusgil et al. 2013). Hence, in the context of high dynamism, firms with stronger KMC make better sense of ambiguous environments and thus, are able to take the right course of actions resulting to better innovation performance. Therefore, it is hypothesized that:

$\mathrm{H}_{2}$ : ED positively moderates the relationship between $\mathrm{KMC}$ and innovation performance, such that KMC are associated with better innovation performance in more dynamic environments.

\subsection{Moderating effect of learning capability (LC)}

Learning capability (LC) can be conceptualized as "a firm's capability to learn from internal and external sources and to adjust or modify its behavior to reflect the new cognitive situation, with a view to improving its performance" (Jerez-Gomez et al. 
2005: 38). The research in the organizational learning area (i.e., Goh and Richards 1997; Jerez-Gomez et al. 2005; Alegre and Chiva 2008) defines LC as a multidimensional construct. Hence, this study proposes five essential dimensions that represent LC: openness and experimentation, risk taking, interaction with the external environment, dialogue and teamwork, and participative decision making. While openness and experimentation can be defined as "the extent to which new ideas and suggestions are attended to and treated sympathetically", risk taking can be understood as "the tolerance of ambiguity, uncertainty, and errors" (Alegre and Chiva 2008: 317). The extent of "the relationships that a firm maintains in its immediate environment" is defined as interaction with the external environment (Alegre and Chiva 2008: 317), and dialogue means a sustained collective inquiry or a basic process that enhances communication and allows people to see the hidden meanings of words (Isaacs 1993; Schein 1993). The last dimension of LC, participative decision making refers to "the level of influence that employees have in the decision-making process" (Alegre and Chiva 2008: 317). Therefore, the measurement of LC will be based on these dimensions. In the literature, the role of LC on the relationship between KMC and innovation performance is conceptualized as LC facilitates KMC resulting to higher innovation performance (Argote et al. 2003; King 2009; Wu and Chen 2014).

Innovation implies "the generation and implementation of new ideas, processes or products" (Alegre and Chiva 2008: 317) and new ideas can be created through $\mathrm{KMC}$ that include the processes of creation, transfer, integration and application of new knowledge. As LC dimensions, whilst openness and experimentation along with dialogue and teamwork expose individuals to a greater variety of unusual ideas and increase internal group cohesion and coordination (Brown and Eisenhardt 1995; Amabile et al. 1996), participative decision making increases involvement and commitment to learn and encourages members of an organization to develop new ideas (Damanpour 1991; Hurley and Hult 1998). Additionally, according to Amabile et al. (1996), risk taking is also necessary for the generation of new ideas and should be tolerated. Therefore, generation and application of new knowledge and ideas can be triggered through internal learning mechanisms. External learning that derives from interaction with the external environment influences KMC as well (Jerez-Gomez et al. 2005; Alegre and Chiva 2008). Establishments of alliances, networks, technology transfers (Calantone et al. 2002), and/or R\&D collaborations with universities and research institutes (Azagra-Caro et al. 2006) may enable firms to obtain new knowledge and ideas. Consequently, with its multi-dimensional nature, LC helps firms generate and embed new ideas and knowledge into organizational processes by facilitating the KMC so that the firms can continuously improve their innovation practices and performance. Therefore, LC plays a moderating role on the link between $\mathrm{KMC}$ and innovation performance. Accordingly, it is proposed that:

$\mathrm{H}_{3}$ : LC positively moderates the relationship between $\mathrm{KMC}$ and innovation performance, such that KMC are associated with better innovation performance under the conditions of higher LC. 


\subsection{Combined effect of ED and LC}

The dynamic resource management perspective which views firm performance as the outcome of a dynamic combination of various influences suggests that performance creation in organizations is a complicated issue and "the ability of a firm to create (innovation) performance is a function of multitude of factors" (Levitas and Ndofor 2006: 139). Accordingly, "a specific structure that matches a certain context will, at a particular period in time, cause a firm to engage in a range of behaviors that give rise to specific outcomes" (Lee et al. 2013: 532). In a similar line, Chen and Miller (2007) state that the contextual factors of the firm and its environment impact the search for external knowledge. The approach that the study adopts is that competition leads to competence approach (Barney and Zajac 1994) which suggests that as uncertainty arising from high environmental dynamism affects the availability of knowledge and constrains their application, firms need to learn more about the environment and then generate new knowledge through more effective KMC leading to better innovation performance (Garriga et al. 2013). Firms develop potentially valuable resources and capabilities to overcome specific competitive challenges. Hence, the impact of $\mathrm{KMC}$ on innovation performance should be examined through an analysis that concerns the interaction effects of other dynamic capabilities under specific contexts in a complementary manner. In this sense, the interplay of ED and LC may compound the situational efficacy of KMC that determine the level of innovation performance. In turbulent environments where high ED exists, firms with greater level of LC develop more effective KMC that lead to better innovation performance. Therefore, we propose that:

$\mathrm{H}_{4}$ : There is a three-way interaction between KMC, LC, and ED, such that in the presence of a high level of ED, the innovation performance effect of KMC is stronger for firms with greater LC.

Based on the above discussions and hypotheses developed, this research establishes a framework that is shown in Fig. 1.

\section{Methodology}

\subsection{Sample and data collection}

Data for this research were obtained through a survey. The sample was selected from the database of Istanbul Chamber of Industry (ISO) that announced the largest 1000 firms of Turkey (ISO-1000) from different sectors annually. This sample which was designed for multiple research purposes was the best available and relevant sample that could be obtained in Turkey. Moreover, availability of detailed updated databases with respect to Turkey as an emerging market was lacking and this database also included the valid names and e-mails of senior-level executives along with the contact addresses of these firms. Although the sampling method chosen seems to be convenient sampling that has sometimes been criticized about its inadequacy to represent entire population and creation of biased samples (Saunders et al. 2007), this sample comprises nearly all prominent firms competing 


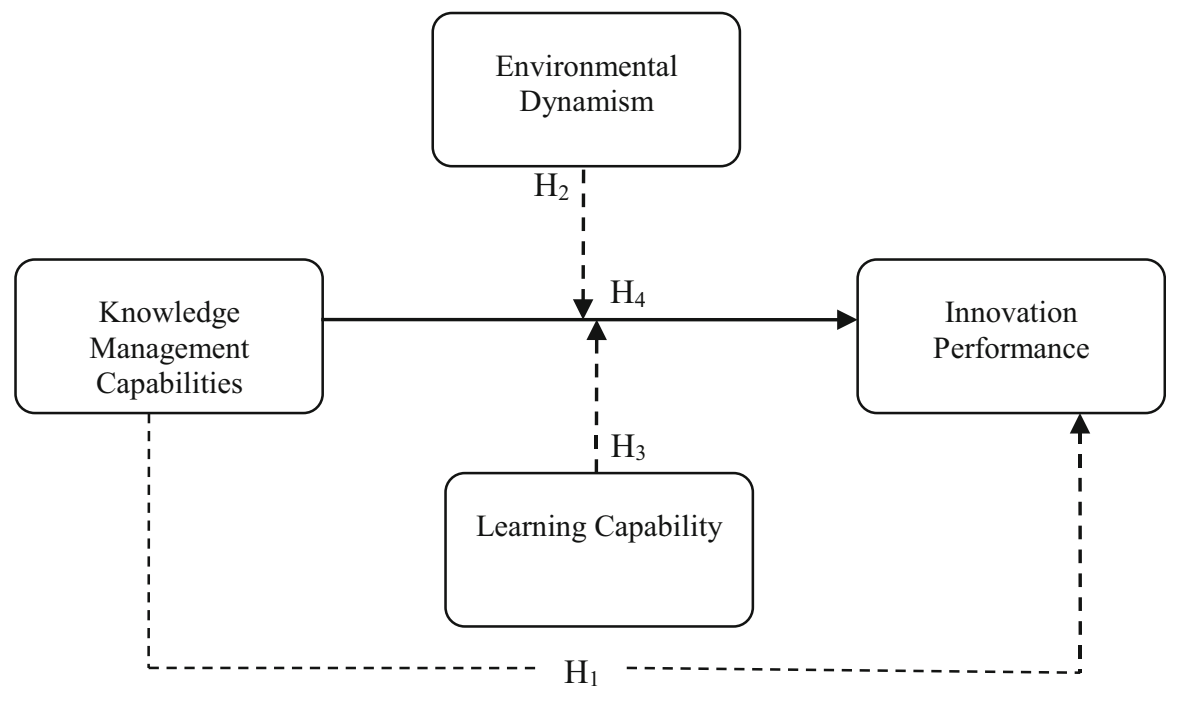

Fig. 1 Conceptual model

in a variety of industries in the Turkish business environment. Some descriptive data about the respondent firms are provided in Table 1. The number of full-time employees ranged from 54 to 29.101. The mean number of employees was 395.18 and the standard deviation was 337.26. Whilst the number of years in business ranged from 4 to 95 , the mean number of years in business was 31.67 and the standard deviation was 29.53.

Primary business activities of the participant firms were automotive, computer and software, textile and apparels, retail, tourism, banking and finance, drugs, oil and petrochemicals, construction, logistics and transportation, telecommunications, and food (see Table 1).

Since the original items of questionnaire were designed in English based on several previous studies on innovation, KMC and ED, it was translated into Turkish by a bilingual associate. Besides, a back translation was completed to check any discrepancy in addition to potential translation errors (Saunders et al. 2007). Following the translation procedure, a pilot study was conducted with 23 seniorlevel managers who had sufficient knowledge about the objectives of the research in the mid of April 2014. The conduct and analysis of pilot study took nearly 2 weeks and it was completed in the first week of May, 2014. The questionnaire included some space at the end of the last section for the feedback of the respondents about how the measurement instrument could be improved. Based on the feedback from the respondents, some modifications were made on the questionnaire. The top or department managers who deal with strategy issues and have adequate knowledge to assess the firm's resource base and performance issues are chosen as the key informants (Hambrick 1987; McKelvie and Davidsson 2009). 
Table 1 Business activities of the firms

\begin{tabular}{lcr}
\hline Business activity & Frequency & Percentage \\
\hline Automotive & 19 & 8.6 \\
Banking and finance & 21 & 9.5 \\
Computer and software & 7 & 3.1 \\
Construction & 18 & 8.1 \\
Drugs & 9 & 4.1 \\
Food & 17 & 7.7 \\
Logistics and transportation & 11 & 5.0 \\
Oil and petrochemicals & 13 & 5.9 \\
Retail & 29 & 13.1 \\
Telecommunications & 3 & 1.4 \\
Textile and apparels & 34 & 15.4 \\
Tourism & 8 & 3.6 \\
Other & 32 & 14.5 \\
Total & 221 & 100.0 \\
\hline
\end{tabular}

Because the unit of analysis in this study is at the firm level, a single informant was used and the questionnaire was mailed to only one executive from each firm. After the pilot study, the questionnaires were sent to the e-mail addresses of the managers as a web-link with a covering letter that assures the privacy and confidentiality of respondents. Two weeks after the initial mailing, a reminder follow-up e-mail was sent and after 3 weeks the third e-mailing was sent to be able to increase the response rate of the study. The administration of survey started in the second week of May, 2014 and finished in the first week of August, 2014. So, the four-phased survey administration including the pilot study and data collection process took nearly 4 months. At the end of the research, a total of 221 useable questionnaires were obtained yielding a response rate of $22.1 \%$.

\subsection{Non-response bias}

To test for non-response bias, the means of early and late respondents on two key demographic variables were compared statistically via independent samples $t$ test (Saunders et al. 2007). Referring to insignificant $t$ statistics, the comparison of early and late respondents did not reveal a significant difference on firm size $(t=-6.834$, $p=.196)$ and age $(t=5.218, p=.173)$.

\subsection{Measurement instrument}

A self-administrated survey questionnaire that consists of four construct categories that are $\mathrm{KMC}, \mathrm{ED}$, and innovation performance constructs along with an additional control variables category was used as the measurement instrument. To account for 
the effects of extraneous variables, firm age, firm size, stage of industry life cycle, and industry structure were controlled.

The questionnaire consisted of a total number of 41 questions: 12 questions to measure the performance effects of KMC, 5 questions for $\mathrm{ED}, 4$ questions for innovation performance, 11 questions for LC, 5 questions to control the effects of industry structure factors, 1 question for the stage of industry's life cycle ( 1 = introduction stage, $2=$ growth stage, $3=$ maturity stage, and $4=$ decline stage), 2 questions for the demographics (age and size), and the last question aimed to categorize the primary business activity of the firms. The items of the questionnaire and their theoretical sources are mentioned in Table 2. Responses to the items were recorded on a 5-point Likert-type scale, where 1 represented total disagreement and 5 total agreement, and reliability along with validity issues were also assessed.

\subsection{Reliability and validity}

To examine the constructs of the research, tests for reliability, convergent and discriminant validity were conducted. Correlations between variables were also examined to assess the presence of multicollinearity. Factor analysis, as a common method, is used to assess convergent validity. In factor analysis, loadings are used to detect whether or not an item appropriately loads on its predicted construct. An exploratory factor analysis with VARIMAX rotation which yields five factors resulted to the theoretically expected factor solutions. Hair (2009) suggests that each item of a scale should be loaded on their predicted construct with a loading level of .50 or higher to confirm construct validity. Except one item that was dropped from the scale, all items were loaded into their stipulated constructs at the .50 level or higher which constitute five factors: KMC, ED, LC, innovation performance and industry structure forces.

Cronbach's alpha coefficients were calculated to test the reliability of the constructs. The constructs that had alpha values equal to and above .70 were accepted as reliable constructs (Nunnally and Bernstein 1994). The reliability analyses show that all constructs possess satisfactory Cronbach's alpha values: KMC $(\alpha=.851)$, ED $(\alpha=.883)$, LC $(\alpha=.869)$, innovation performance $(\alpha=.874)$, and industry structure forces $(\alpha=.809)$.

Apart from the item loadings and Cronbach's alpha values, convergent validity was assessed by the third criterion: average variance extracted (AVE) for each construct should be larger than .50 (Chin et al. 2003). As reported in Tables 2 and 3, item loadings, AVE scores, and alpha values of all constructs were at the satisfactory ranges. Therefore, reliability and convergence validity were supported in this data set.

Discriminant validity is established when the items that measure a construct are not perfectly correlated with measures from other constructs from which they are supposed to differ (Hair 2009). Independence of the predictor (independent) variables is important in statistical testing since highly correlated independent variables can predict each other and may cause problems with multicollinearity which influence the accuracy of the regression analysis negatively (Hair 2009). This 
Table 2 Items of the questionnaire, factor loadings and Cronbach alpha coefficients

\begin{tabular}{|c|c|c|c|}
\hline Variables & Items & Loadings & $\alpha$ \\
\hline \multirow[t]{12}{*}{$\begin{array}{l}\text { Knowledge Management } \\
\text { Capabilities (KMC) (Alavi } \\
\text { and Leidner 2001; Gold } \\
\text { et al. 2001; Tanriverdi } \\
\text { 2005; Wu and Chen 2014) }\end{array}$} & $\begin{array}{l}\text { Our firm has capability to distribute relevant } \\
\text { knowledge throughout the organization (via } \\
\text { collaborative platforms, social software, blogs, } \\
\text { wikis, etc.) }\end{array}$ & .932 & \\
\hline & $\begin{array}{l}\text { Our firm has capability to share relevant knowledge } \\
\text { among business units }\end{array}$ & .906 & \\
\hline & $\begin{array}{l}\text { Our firm has capability to develop knowledge from } \\
\text { internal and external knowledge sources (via IT } \\
\text { systems, call centers, CRM, ERP, supply chain, } \\
\text { logistics systems, etc.) }\end{array}$ & .874 & \\
\hline & $\begin{array}{l}\text { Our firm has capability to transfer relevant knowledge } \\
\text { to employees }\end{array}$ & .861 & .851 \\
\hline & $\begin{array}{l}\text { Our firm has capability to apply knowledge to } \\
\text { develop new products/services }\end{array}$ & .835 & \\
\hline & $\begin{array}{l}\text { Our firm has capability to organize and manage } \\
\text { knowledge }\end{array}$ & .811 & \\
\hline & $\begin{array}{l}\text { Our firm has capability to apply knowledge to solve } \\
\text { new problems }\end{array}$ & .792 & \\
\hline & $\begin{array}{l}\text { Our firm has capability to apply knowledge to change } \\
\text { competitive conditions }\end{array}$ & .749 & \\
\hline & $\begin{array}{l}\text { Our firm has capability to store acquired knowledge } \\
\text { into organizational knowledge repository }\end{array}$ & .743 & \\
\hline & $\begin{array}{l}\text { Our firm has capability to integrate different sources } \\
\text { and types of knowledge }\end{array}$ & .698 & \\
\hline & $\begin{array}{l}\text { Our firm has capability to codify acquired knowledge } \\
\text { into accessible and applicable formats }\end{array}$ & .655 & \\
\hline & $\begin{array}{l}\text { Our firm has capability to interpret new knowledge on } \\
\text { the basis of prior knowledge } \mathrm{a}^{\mathrm{a}}\end{array}$ & $.473^{\mathrm{a}}$ & \\
\hline \multirow{5}{*}{$\begin{array}{l}\text { Environmental Dynamism } \\
\quad \text { (ED) (Jansen et al. 2009; } \\
\text { Zhou and Wu 2010) }\end{array}$} & $\begin{array}{l}\text { In our local market, changes are taking place } \\
\text { continuously }\end{array}$ & .944 & \\
\hline & $\begin{array}{l}\text { Environmental changes in our local market are } \\
\text { intense }\end{array}$ & .903 & .833 \\
\hline & The technology in this industry is changing rapidly & .879 & \\
\hline & $\begin{array}{l}\text { Our clients regularly ask for new products and } \\
\text { services }\end{array}$ & .823 & \\
\hline & $\begin{array}{l}\text { In our market, the volumes of products and services to } \\
\text { be delivered change fast and often }\end{array}$ & .816 & \\
\hline
\end{tabular}


Table 2 continued

\begin{tabular}{|c|c|c|c|}
\hline Variables & Items & Loadings & $\alpha$ \\
\hline \multirow{11}{*}{$\begin{array}{l}\text { Learning Capability (LC) } \\
\text { (Amabile et al. 1996; } \\
\text { Pedler et al. 1997; Alegre } \\
\text { and Chiva 2008) }\end{array}$} & Employees are encouraged to communicate & .956 & \\
\hline & $\begin{array}{l}\text { Policies are significantly influenced by the } \\
\text { employees' views }\end{array}$ & .949 & \\
\hline & People feel involved in main company decisions & .922 & \\
\hline & $\begin{array}{l}\text { People are encouraged to interact with the } \\
\text { environment: competitors, customers, } \\
\text { technological institutes, universities, suppliers, etc. }\end{array}$ & .894 & \\
\hline & $\begin{array}{l}\text { People here receive support and encouragement when } \\
\text { presenting new ideas }\end{array}$ & .885 & .869 \\
\hline & $\begin{array}{l}\text { Initiative often receives a favorable response here, so } \\
\text { people feel encouraged to generate new ideas }\end{array}$ & .882 & \\
\hline & $\begin{array}{l}\text { There is a free and open communication within my } \\
\text { work group }\end{array}$ & .871 & \\
\hline & $\begin{array}{l}\text { People are encouraged to take risks in this } \\
\text { organization }\end{array}$ & .866 & \\
\hline & $\begin{array}{l}\text { Managers in this organization frequently involve } \\
\text { employees in important decisions }\end{array}$ & .857 & \\
\hline & Cross-functional teamwork is a common practice here & .804 & \\
\hline & $\begin{array}{l}\text { There are systems and procedures for receiving, } \\
\text { collating and sharing information from outside the } \\
\text { company }\end{array}$ & .789 & \\
\hline \multirow{5}{*}{$\begin{array}{l}\text { Innovation Performance } \\
\text { (Jansen et al. 2009; } \\
\text { Terziovski 2010; Wei et al. } \\
\text { 2014) }\end{array}$} & $\begin{array}{l}\text { In the last } 3 \text { years, compared to our major } \\
\text { competitors, our firm is more successful in terms } \\
\text { of: }\end{array}$ & & \\
\hline & Success of new products launched & .928 & \\
\hline & Accelerated speed to market & .917 & \\
\hline & Number of new product configurations & .894 & .874 \\
\hline & Improved work methods and processes & .836 & \\
\hline \multirow[t]{5}{*}{$\begin{array}{l}\text { Industry Structure Forces } \\
\quad \text { (Porter 1980) }\end{array}$} & $\begin{array}{l}\text { The number of competitors vying for customers in our } \\
\text { industry is (Very low-Very high) }\end{array}$ & .911 & \\
\hline & $\begin{array}{l}\text { How easy is it for new firms to enter and compete in } \\
\text { your industry (Very easy-Very difficult) }\end{array}$ & .882 & \\
\hline & $\begin{array}{l}\text { What level of bargaining power (i.e., ability to } \\
\text { negotiate lower prices) do you have over your } \\
\text { suppliers (Very weak-Very strong) }\end{array}$ & .859 & .809 \\
\hline & $\begin{array}{l}\text { What level of bargaining power (i.e., ability to } \\
\text { negotiate lower prices) do customers have over } \\
\text { your firm (Very weak-Very strong) }\end{array}$ & .845 & \\
\hline & $\begin{array}{l}\text { To what degree is your industry threatened by } \\
\text { substitute products/services (No threat-Extreme } \\
\text { threat) }\end{array}$ & .773 & \\
\hline
\end{tabular}

Kaiser-Meyer-Olkin sampling adequacy .873

Barttlet's test of approx. Chi-square sphericity 130,65.286 $(p<.001)$

a Dropped item 
situation necessitates the examination of the inter-correlations between independent variables. To assess discriminant validity and evaluate the measures, the criterion that the square root of AVE for each construct should be larger than its correlations with all other constructs was used (Chin et al. 2003). The means, standard deviations, square root of AVE of each construct, and correlation coefficients of all the variables used to test the hypotheses are presented in Table 3.

Although some significant inter-correlations between the independent variables were observed, none of the correlation coefficient was above the level considered to be serious, which is generally accepted as .80 or higher (Saunders et al. 2007; Hair 2009). Moreover, variance inflation factors (VIF) were also below the score recommended as problematic, which is 5 (Hair et al. 2013). Accordingly, moderate levels of correlations among the independent variables do not seem to create multicollinearity problem.

This level of inter-correlations does not only indicate the distinct nature of the variables, but it also ensures their unique contributions to the overall model (Hair 2009). Additionally, as shown in Table 3, the square root of AVE for each construct (Industry Structure Forces, KMC, LC, ED, and Innovation Performance) was larger than its correlations with all other constructs. Therefore, the discriminant validity criterion was addressed.

\subsection{Assessing common method bias}

Since this study uses subjective measures for dependent and independent variables, there is a risk for common method bias which results from the fact that the respondents provide these measures by a common rater (Podsakoff et al. 2003). To examine the existence of common method bias, Harman's single-factor test was conducted. Five factors were drawn out and the largest factor explained $24.32 \%$ of the total variance.

Therefore, no single factor has explained the majority of the total variance leading to the conclusion of the inexistence of common method bias. Additionally, a confirmatory factor analysis (CFA) was conducted to compare the fit indexes of a multi-factor model and a single overall latent factor model in which all items designed for the questionnaire were loaded (Anderson and Gerbing 1988).

Results showed that the multi-factor model fits the data $\left[\chi^{2}=141.587, p<.05\right.$; comparative fit index $(\mathrm{CFI})=.943$; goodness of fit index $(\mathrm{GFI})=.945$; route mean square error of approximation $(\mathrm{RMSEA})=.063$; non-normed fit index $(\mathrm{NNFI})=.931]$ considerably better than the one-factor model $\left[\chi^{2}=183.628\right.$, $p<.05 ;(\mathrm{CFI})=.721 ;(\mathrm{GFI})=.704 ;(\mathrm{RMSEA})=.096 ;(\mathrm{NNFI})=.713]$, indicating that no serious threat of common method bias exists in the research.

\subsection{Hypothesis testing}

Multiple regression analyses and moderated method were used to test the above proposed direct and interactive hypotheses. A five-step hierarchical analysis was conducted. In hierarchical regression method, each set of independent variables is entered into separate blocks for analysis and the incremental changes of the $R^{2}$ 


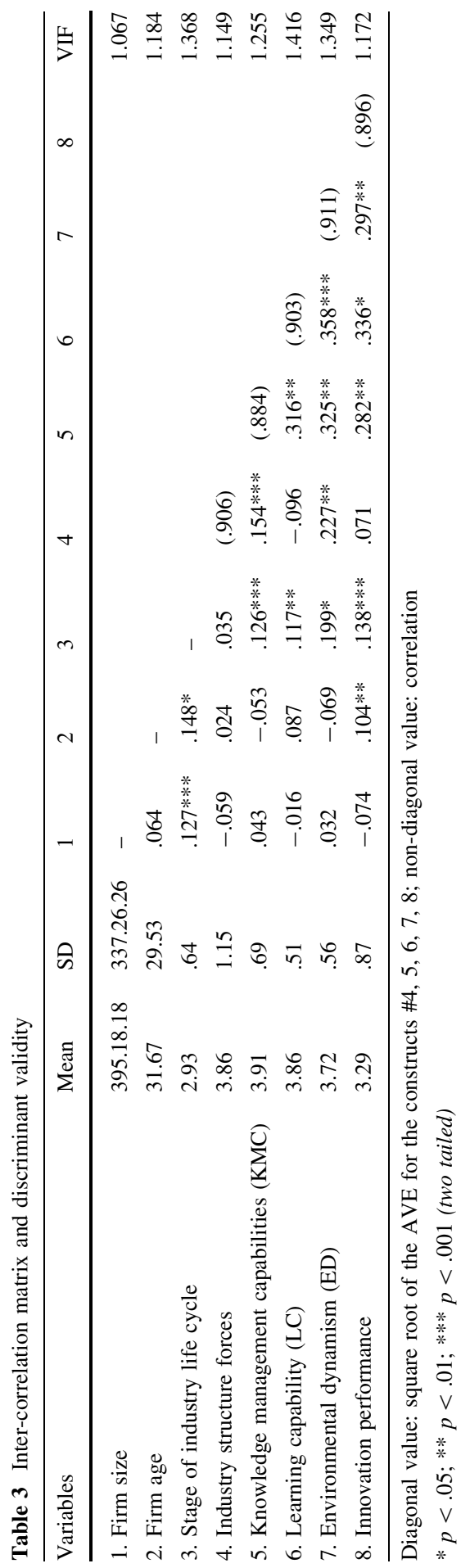


statistic and the $\beta$ coefficients are calculated. The control variables were first entered and then knowledge management capabilities (KMC) variable was entered in the second step. Moderating variables that are ED and LC were entered in the third step. The two-way interaction terms $(\mathrm{KMC} \times \mathrm{ED})$ and $(\mathrm{KMC} \times \mathrm{LC})$ were entered in the fourth step. Finally, the three-way interaction of $(\mathrm{KMC} \times \mathrm{ED} \times \mathrm{LC})$ was entered in the fifth step to predict innovation performance.

\section{Results}

The results of regression analyses are given in Table 4. In Model 1, just the control variables, including firm age, firm size, stage of industry life cycle and industry structure factors were entered and no significant association was observed between the control variables and innovation performance. In Model 2, KMC was added and a positively significant relationship between $\mathrm{KMC}$ and innovation performance $\left(\beta=.314^{* * *}, p<.001\right)$ was found. Besides, the entrance of KMC provided an additional significant explanation power $14.3 \%\left(\Delta R^{2}=.143 ; F=1.945 * * *\right.$, $p<.001)$ in the variation of innovation performance. Therefore, $\mathrm{H}_{1}$ is supported.

ED as the moderator was entered in Model 3, and it had a significant effect on innovation performance $(\beta=.139 * *, p<.01)$. Similarly, LC as another moderator was entered in Model 3 and a significant effect on innovation performance was observed $\left(\beta=.172^{*}, p<.05\right)$. The entrance of ED and LC also provided an additional significant explanation power $10.7 \%\left(\Delta R^{2}=.107 ; \quad F=2.573 * * *\right.$,

Table 4 The results of regression analyses

\begin{tabular}{|c|c|c|c|c|c|}
\hline \multirow[t]{2}{*}{ Predictors } & \multicolumn{5}{|c|}{ Innovation performance } \\
\hline & $\begin{array}{l}\text { Model } \\
1\end{array}$ & Model 2 & Model 3 & Model 4 & Model 5 \\
\hline 1. Firm age & .051 & .043 & .029 & .047 & .044 \\
\hline 2. Firm size & .069 & .061 & .053 & .054 & .067 \\
\hline 3. Industry structure forces & -.037 & -.026 & .018 & .012 & -.081 \\
\hline 4. Stage of industry life cycle & $-.102 *$ & -.072 & -.061 & -.038 & .004 \\
\hline $\begin{array}{l}\text { 5. Knowledge management capabilities } \\
\text { (KMC) }\end{array}$ & & $.314 * * *$ & $.243 * * *$ & $.229 * *$ & $.207 * *$ \\
\hline 6. Environmental dynamism (ED) & & & $.139 * *$ & $.104 * * *$ & $.116^{* * *}$ \\
\hline Learning capability (LC) & & & $.172 *$ & $.156^{*}$ & $.131 * *$ \\
\hline 7. $\mathrm{KMC} \times \mathrm{ED}$ & & & & $.371 * *$ & \\
\hline $\mathrm{KMC} \times \mathrm{LC}$ & & & & $.435 * *$ & \\
\hline 8. $\mathrm{KMC} \times \mathrm{ED} \times \mathrm{LC}$ & & & & & $.503 * * *$ \\
\hline$R^{2}$ & .086 & .229 & .336 & .452 & .585 \\
\hline$\Delta R^{2}$ & - & .143 & .107 & .116 & .133 \\
\hline$F$ value & 1.123 & $1.945 * * *$ & $2.573 * * *$ & $2.891 * * *$ & $3.364 * * *$ \\
\hline
\end{tabular}


$p<.001)$ in the variation of innovation performance. In testing the moderation effect in Model 4, the joint effects of KMC and $\operatorname{ED~}\left(\beta=.371^{* *}, p<.01\right)$, and $\mathrm{KMC}$ and $\mathrm{LC}\left(\beta=.435^{* * *}, p<.001\right)$ were significant on innovation performance. Moreover, the joint effects of KMC and ED, and $\mathrm{KMC}$ and $\mathrm{LC}$ added a significant contribution $11.6 \%\left(\Delta R^{2}=.116 ; F=2.891 * * *, p<.001\right)$ in explaining the variation in innovation performance.

Thus, based on the $\beta$ coefficients and significant $R^{2}$ changes, $\mathrm{H}_{2}$ and $\mathrm{H}_{3}$ are confirmed. Finally, the three-way interaction effect of KMC, ED and LC was entered in Model 5. Whilst the three-way interaction of these variables provided a significant effect with the highest beta value $\left(\beta=.503^{* * *}, p<.001\right)$, their contribution to explain the performance variation was the greatest $\left(\Delta R^{2}=.133\right.$; $\left.F=3.364^{* * *}, p<.001\right)$. This result led to the confirmation of $\mathrm{H}_{4}$.

\section{Discussion}

This research seeks to extend our understanding on how environment as a contextual factor and knowledge management and learning as dynamic capabilities can affect innovation performance of firms. Our research findings contribute to the current study of innovation by highlighting the importance of KMC, LC and relevance of environment in impacting the effects of KMC in a number of ways. First, this study once more showed the critical role of knowledge management on innovation performance (Van Wijk et al. 2008; Wu and Chen 2014). Knowledge assets are the basic form to realize innovation performance, but the real value would be created and positive results would be achieved through managing static knowledge assets in an organized manner and processing them effectively.

Second, the study proposed that the impact of KMC would be stronger on innovation performance under high levels of ED. The hypothesis was tested and found support for this proposition. The effect of KMC on innovation performance was stronger when ED was high. Moreover, explanatory power of the interaction effects of KMC and ED was higher for the variations in innovation performance. This shows that high level of ED makes the positive linkage between KMC and innovation performance stronger thereby ED forces firms to assimilate and use new information better, create more new product configurations and move readily to new markets. In this sense, ED moderates the relationship between KMC and innovation performance.

In fact, this research helped to the efforts of researchers to have a clearer understanding about the two somewhat contradictory positions that exist in the strategic management literature with respect to the value of dynamic capabilities under different levels of ED (Schilke 2014) through providing new evidence. The majority of the scholars in the area suggests that the DC effect on performance is comparatively higher at high levels of dynamism (Drnevic and Kriauciunas 2011; Helfat and Winter 2011; Zahra et al. 2006) while the others raise doubt about their effectiveness in highly dynamic environments (Eisenhardt and Martin 2000; Schreyögg and Kliesch-Eberl 2007). 
Our findings support the idea that DC effect on performance can be higher at high levels of dynamism. One explanation for this finding may be linked to the specific economic, social and political conditions of the countries in which the firms operate. For example, rapid and discontinuous changes are common in Turkish economy where a high ED occurs. Moreover, related to different local cultures, ethnic foundations, regional traditions and religious sects and varieties in lifestyles, social values, education levels and linguistics throughout the country, consumer preferences are very divergent in Turkey. Additionally, the consumption patterns of Turkish people were shaped by attractive shopping malls that offer a great variety of and fast proliferating "new and improved" goods and the notion of the "good life," and "modernity" was tied to the consumption of flashy, trendy and fashionable new products (Sandikci and Ger 2005). Under these conditions, the continuous introduction of product improvements and the development of new products are imperative for firms in the country. Therefore, to exploit opportunities and sustain competitive advantage, Turkish firms may have given priority on offering as many as new product configurations rapidly to the dynamic market where fast-changing consumption preferences exist and used their KMC especially for this aim. Turbulent and competitive environment may have compelled the firms to focus on addressing the increasing new product demands of impatient consumers rapidly and giving most of their efforts to design, creative thinking, marketing, and quick production issues.

For the moderator of LC, this study found that LC enhanced the positive relationship between KMC and innovation. Learning from the internal and external sources is crucial to create new knowledge. Moreover, new knowledge would not automatically improve innovation ability of a firm unless they are first learned by the employees. When LC in an organization is high, organizational employees can absorb existing knowledge assets well and operationalize $\mathrm{KMC}$ in a more effective manner. So, LC, as a facilitator, enhances the power of KMC as the basic driver of innovation performance.

The last noteworthy finding was that the interactive effects of the two capabilities (KMC and LC) on innovation performance were strongest when environmental dynamism was high. Namely, when all dynamic capabilities and appropriate environmental conditions worked together, a stronger synergy resulting to better performance was created. Hence, it is likely to state that the firms which operated in high ED have given priority to increase innovation performance by reconfiguring their KMC, enhancing their LC, and recombining the existing knowledge repositories in line with the specific requirements of the dynamic market. This finding is consistent with the proposition of dynamic capabilities view which suggests that the presence and efficacy of dynamic capabilities has been equated with environmental conditions characterized by high dynamism (Sirmon et al. 2008; Schilke 2014). Besides, the efficacy of a dynamic capability is contingent to the availability and effectiveness of other resources and capabilities and thereby through the synergistic effects that emerge as a result of the complex interactions of resources and capabilities, new resource bundles can be created for better firm performance (Zahra et al. 2006; Sirmon et al. 2007, 2011). In parallel, this study 
found that the effectiveness of KMC leading to innovation performance in highly dynamic markets was contingent to another dynamic capability that was LC.

As a managerial implication, within the context of Turkish business environment, given the divergent and fast-changing consumer attitudes, wide geographical area, and difficult and harsh business conditions in the country, possession of the mechanisms that can improve learning ability help firms to monitor potential environmental and political shocks, changes and customer shifts and provide precautionary signals as a necessity. In this situation, effective information technology (IT), enterprise resource planning (ERP), and supply chain management (SCM) systems help firms to address market needs (i.e., changing product ranges and/or accelerating product logistics) rapidly. Additionally, creation of new knowledge or revelation of existing tacit and embedded knowledge, distribution of knowledge throughout the organization, and provision of sufficient intelligence pertaining to current and future customer needs, competitor strategies and actions, channel requirements, and the broader business environment can be boosted through different kinds of social software tools. Besides, flat organizational structures where low hierarchy exists can increase sharing of knowledge in the organization. The development of a learning organization with its internal and external parties should be integrated to the vision of firms. Yet, it should be noted that resource allocation along with the optimal deployment of strategic resources is a key managerial challenge, and given the scarcity in resource availability, priority should be given to the most important ones.

\subsection{Limitations and future research}

This research has some limitations like other studies. First, the sample is limited to a Turkish business database. Turkey is a big and dynamic emerging market and Turkish firms may provide sufficient information for the examination of the relationships between KMC, LC and ED. However, reliability of the findings should be subject to further testing and refinement across multiple settings, industries and countries through longitudinal studies where possible.

In all research, objective performance measures should be used where possible and available since subjective performance evaluations may not be the perfect substitutes of objective measures. However, given the nature of the research (i.e., gathering information about time to market) and limitation of obtaining some secondary data (i.e., number of new product configurations), this research used perception-based performance measurement. Although subjective perceptual measures from upper level management teams can be considered as an accurate, if not perfect, substitute of objective performance measures (Dess and Robinson 1984; Venkatraman and Ramanujam 1987), it should be noted that performance evaluations of the managers might produce biased results. Objective measures, such as R\&D intensity and number of patents, can be useful for validating the propositions of the study.

The findings of research rely solely on the judgments of key respondents. Using such a research technique may create concerns especially when a single informant fills out items that tap into independent and dependent variables within the same 
survey instrument. Moreover, although the measurement instrument was sent to the personal e-mail addresses of the key respondents, some issues concerning the reliability of data may arise because it is not possible to know whether the questionnaires were filled by the key respondents or not.

Lastly, a construct set that includes a broader but not exhaustive number of resources and capabilities might be helpful for a better investigation of resource and capability and innovation performance. More sophisticated models that use other influential factors such as learning ability, human capital, and social capital in the same model may provide more exploratory results for innovation performance.

Open Access This article is distributed under the terms of the Creative Commons Attribution 4.0 International License (http://creativecommons.org/licenses/by/4.0/), which permits unrestricted use, distribution, and reproduction in any medium, provided you give appropriate credit to the original author(s) and the source, provide a link to the Creative Commons license, and indicate if changes were made.

\section{References}

Alavi, M., and D.E. Leidner. 2001. Knowledge management and knowledge management systems: Conceptual foundations and research issues. MIS Quarterly 25: 107-136.

Alegre, J., and R. Chiva. 2008. Assessing the impact of organizational learning capability on product innovation performance: An empirical test. Technovation 28: 315-326.

Amabile, T., R. Conti, H. Coon, J. Lazenby, and M. Herron. 1996. Assessing the work environment for creativity. Academy of Management Journal 39: 1154-1184.

Amabile, T.M. 1996. Creativity in context. Boulder, CO: Westview.

Ambrosini, V., and C. Bowman. 2009. What are dynamic capabilities and are they a useful construct in strategic management? International Journal of Management Reviews 11: 29-49.

Anand, G., J. Gray, and E. Siemsen. 2012. Decay, shock, and renewal: Operational routines and process entropy in the pharmaceutical industry. Organization Science 23: 1700-1716.

Anderson, J.C., and D.W. Gerbing. 1988. Structural equation modeling in practice: A review and recommended two-step approach. Psychological Bulletin 103: 411-423.

Anderson, N., K. Potočnik, and J. Zhou. 2014. Innovation and creativity in organizations: A state-of-thescience review, prospective commentary, and guiding framework. Journal of Management 40: 1297-1333.

Argote, L., B. McEvily, and R. Reagans. 2003. Managing knowledge in organizations: An integrative framework and review of emerging themes. Management Science 49: 571-582.

Azagra-Caro, J.M., F. Archontakis, A. Gutierrez-Gracia, and I. Fernandez de Lucio. 2006. Faculty support for the objectives of university-industry relations versus degree of R\&D cooperation: The importance of regional absorptive capacity. Research Policy 35: 37-55.

Bansemir, B., A.K. Neyer, and K.M. Möslein. 2012. Knowledge exchange in intra-organizational innovation communities: The role of cognitive and affective states. Business Research 5: 43-58.

Barney, J.B. 1991. Firm resources and sustained competitive advantage. Journal of Management 17: 99-120.

Barney, J.B., and E.J. Zajac. 1994. Competitive organizational behavior: Toward an organizationally based theory of competitive advantage. Strategic Management Journal 15: 5-9.

Becker, M.C. 2004. Organizational routines: A review of the literature. Industrial and Corporate Change 13: 643-677.

Bell, G.G., and A. Zaheer. 2007. Geography, networks, and knowledge flows. Organization Science 18: 955-972.

Brown, S.L., and K.M. Eisenhardt. 1995. Product development: Past research, present findings, and future directions. Academy of Management Review 20: 343-378.

Calantone, R.J., S.T. Cavusgil, and Y. Zhao. 2002. Learning orientation, firm innovation capability, and firm performance. Industrial Marketing Management 31: 515-524. 
Cavusgil, E., S.H. Seggie, and M.B. Talay. 2007. Dynamic capabilities view: Foundations and research agenda. Journal of Marketing Theory and Practice 15: 159-166.

Cavusgil, T., P.N. Ghauri, and A.A. Akcal. 2013. Doing business in emerging markets, 2nd ed. London: Sage Publications.

Chen, W.R., and K.D. Miller. 2007. Situational and institutional determinants of firms' R\&D search intensity. Strategic Management Journal 28: 369-381.

Chin, W.W., B.L. Marcolin, and P.R. Newstead. 2003. A partial least squares latent variable modeling approach for measuring interaction effects: Results from a Monte Carlo simulation study and an electronic-mail emotion/adoption study. Information Systems Research 14: 189-217.

D'Aveni, R. 1994. Hypercompetition. New York: Free Press.

Damanpour, F. 1991. Organizational innovation: a meta-analysis of effects of determinants and moderators. Academy of Management Journal 34:555-590.

Darroch, J. 2005. Knowledge management, innovation and firm performance. Journal of Knowledge Management 9: 101-115.

Davenport, T.H., and L. Prusak. 2000. Working knowledge: How organizations manage that they know. New York: McGraw-Hill.

Dess, G.G., and R.B. Robinson. 1984. Measuring organizational performance in the absence of objective measures: The case of the privately-held firm and conglomerate business unit. Strategic Management Journal 5: 265-273.

Dionysiou, D.D., and H. Tsoukas. 2013. Understanding the (re)creation of routines from within: A symbolic interactionist perspective. Academy of Management Review 38: 181-205.

Drnevic, P.L., and P.A. Kriauciunas. 2011. Clarifying the conditions and limits of the contributions of ordinary and dynamic capabilities to relative firm performance. Strategic Management Journal 32: 254-279.

Droge, C., C. Claycomb, and R. Germain. 2003. Does knowledge mediate the effect of context on performance? Some initial evidence. Decision Sciences 34: 541-568.

Easterby-Smith, M., and M. Lyles. 2003. The Blackwell handbook of organizational learning and knowledge management. Oxford: Blackwell.

Easterby-Smith, M., and I.M. Prieto. 2008. Dynamic capabilities and knowledge management: An integrative role for learning? British Journal of Management 19: 235-249.

Eisenhardt, K.M. 1989. Making fast strategic decisions in high-velocity environments. Academy of Management Journal 32: 543-576.

Eisenhardt, K.M., and J. Martin. 2000. Dynamic capabilities: What are they? Strategic Management Journal 21: 1105-1121.

Garg, V.K., B.A. Walters, and R.L. Priem. 2003. Chief executive scanning emphases, environmental dynamism, and manufacturing firm performance. Strategic Management Journal 24: 725-744.

Garriga, H., G. von Krogh, and S. Spaeth. 2013. How constraints and knowledge impact open innovation. Strategic Management Journal 34:1134-1144.

Goh, S., and G. Richards. 1997. Benchmarking the learning capability of organizations. European Management Journal 15: 575-583.

Gold, A.H., A. Malhotra, and A.H. Segars. 2001. Knowledge management: An organizational capabilities perspective. Journal of Management Information Systems 18: 185-214.

González-Benito, J., H. Aguinis, B.K. Boyd, and I. Suárez-González. 2012. Coming to consensus on strategic consensus: A mediated moderation model of consensus and performance. Journal of Management 38: 1685-1714.

Grant, R.M. 1996. Prospering in dynamically-competitive environments: Organizational capability as knowledge integration. Organization Science 7: 375-387.

Grant, R.M. 1997. The knowledge-based view of the firm: Implications for management practice. Long Range Planning 30: 450-454.

Grant, R.M., and C. Baden-Fuller. 2004. A knowledge accessing theory of strategic alliances. Journal of Management Studies 41: 61-84.

Hair, J.F., W.C. Black, B.J. Babin, and R.E. Anderson. 2009. Multivariate data analysis, 7th ed. Englewood Cliff, NJ: Prentice Hall.

Hair, J.F., G.T.M. Hult, C.M. Ringle, and M. Sarstedt. 2013. A primer on partial least squares structural equation modeling (PLS-SEM). Thousand Oaks: Sage.

Hambrick, D.C. 1987. Top management teams: Key to strategic success. California Management Review 30: $88-108$. 
Hegde, D., and P. Shapira. 2007. Knowledge, technology trajectories, and innovation in a developing country context: Evidence from a survey of Malaysian firms. International Journal of Technology Management 40: 349-370.

Helfat, C.E., and M.A. Peteraf. 2003. The dynamic resource-based view: Capability lifecycles. Strategic Management Journal 24: 997-1010.

Helfat, C.E., and S.G. Winter. 2011. Untangling dynamic and operational capabilities: Strategy for the (n)ever-changing world. Strategic Management Journal 32: 1243-1250.

Hoskisson, R.E., L. Eden, C.M. Lau, and M. Wright. 2000. Strategies in emerging economies. Academy of Management Journal 43: 249-267.

Hurley, R.F., and G.T.M. Hult. 1998. Innovation, market orientation, and organizational learning: an integration and empirical examination. Journal of Marketing 62:42-54.

Isaacs, W. 1993. Dialogue, collective thinking, and organizational learning. Organizational Dynamics 22: 24-39.

Jansen, J.J.P., F.A.J. Van den Bosch, and H.W. Volberda. 2006. Exploratory innovation, exploitative innovation, and performance: Effects of organizational antecedents and environmental moderators. Management Science 52: 1661-1674.

Jansen, J.J.P., D. Vera, and M. Crossan. 2009. Strategic leadership for exploration and exploitation: The moderating role of environmental dynamism. The Leadership Quarterly 20: 5-18.

Jerez-Gomez, P., J. Cespedes-Lorente, and R. Valle-Cabrera. 2005. Organizational learning capability: A proposal of measurement. Journal of Business Research 58: 715-725.

Joshi, K.D., L. Chi, A. Datta, and S. Han. 2010. Changing the competitive landscape: Continuous innovation through IT-enabled knowledge capabilities. Information Systems Research 21: 472-495.

Kamal, S. 2011. Entry mode and subsidiary performance in emerging economies. Mustang Journal of Business and Ethics 2: 20-29.

King, W.R. 2009. Knowledge management and organizational learning. US: Springer.

Lee, C.-Y., H.-L. Wu, and C.-Y. Liu. 2013. Contextual determinants of ambidextrous learning: Evidence from industrial firms in four industrialized countries. IEEE Transactions on Engineering Management 60: 529-540.

Lee, H., and B. Choi. 2003. Knowledge management enablers, processes, and organizational performance: An integrative view and empirical examination. Journal of Management Information Systems 20: 179-228.

Levinthal, D.A., and J.G. March. 1993. The myopia of learning. Strategic Management Journal 14: 95-112.

Levitas, E., and H.A. Ndofor. 2006. What to do with the resource-based view: A few suggestions for what ails the RBV that supporters and opponents might accept. Journal of Management Inquiry 15: 135-144.

Lewin, A.Y., C.P. Long, and T.N. Carroll. 1999. The coevolution of new organizational forms. Organization Science 10: 535-550.

Liu, H., X. Jiang, J. Zhang, and X. Zhao. 2013. Strategic flexibility and international venturing by emerging market firms: The moderating effects of institutional and relational factors. Journal of International Marketing 21: 79-98.

McKelvie, A., and P. Davidsson. 2009. From resource base to dynamic capabilities: An investigation of new firms. British Journal of Management 20: 63-80.

Mitchell, V.L. 2006. Knowledge integration and information technology performance. MIS Quarterly 30: 919-939.

Molina-Castillo, F.-J., and J.-L. Munuera-Aleman. 2009. New product performance indicators: Time horizon and importance attributed by managers. Technovation 29: 714-724.

Moos, B., and D. Beimborn. 2013. The role of knowledge management systems for innovation: An absorptive capacity perspective. International Journal of Innovation Management 17: 1-30.

Nonaka, I. 1994. A dynamic theory of organizational knowledge creation. Organization Science 5: 14-37.

Nunnally, J., and I. Bernstein. 1994. Psychometric theory. New York: McGraw Hill.

O'Connor, G.C. 2008. Major innovation as a dynamic capability: A systems approach. Journal of Product Innovation Management 25: 313-330.

Palacios, D., I. Gil, and F. Garrigos. 2009. The impact of knowledge management on innovation and entrepreneurship in the biotechnology and telecommunications industries. Small Business Economics 32: 291-301.

Pedler, M., J. Burgoyne, and T. Boydell. 1997. The learning company: A strategy for sustainable development. Maidenhead: McGrawHill. 
Phelps, C., R. Heidl, and A. Wadhwa. 2012. Knowledge, networks, and knowledge networks: A review and research agenda. Journal of Management 38: 1115-1166.

Podsakoff, P.M., S.B. Mackenzie, J. Lee, and N.P. Podsakoff. 2003. Common method biases in behavioral research: A critical review of the literature and recommended remedies. Journal of Applied Psychology 88: 879-903.

Porter, M.E. 1980. Competitive strategy. New York, NY: The Free Press.

Ramamurti, R. 2012. Competing with emerging market multinationals. Business Horizons 55: 241-249.

Ray, G., J.B. Barney, and W.A. Muhanna. 2004. Capabilities, business processes, and competitive advantage: Choosing the dependent variable in empirical tests of the resource-based view. Strategic Management Journal 25: 23-37.

Ray, G., L. Xue, and J.B. Barney. 2013. Impact of information technology capital on firm scope and performance: The role of asset characteristics. Academy of Management Journal 56: 1125-1147.

Rosing, K., M. Frese, and A. Bausch. 2011. Explaining the heterogeneity of the leadership-innovation relationship: Ambidextrous leadership. The Leadership Quarterly 22: 956-974.

Salvato, C., and C. Rerup. 2011. Beyond collective entities: Multilevel research on organizational routines and capabilities. Journal of Management 37: 468-490.

Sandikci, O., and G. Ger. 2005. Contemporary Turkish consumption landscape: Polarity and plurality. In New emerging economies and their culture, ed. J. Prasnikar, and A. Cirman, 139-153. Slovenia: Nova.

Saunders, M., P. Lewis, and A. Thornhill. 2007. Research methods for business students, 4th ed. Essex: Pearson Education.

Schein, E.H. 1993. On dialogue, culture, and organizational learning. Organizational Dynamics 22: $40-51$.

Schilke, O. 2014. On the contingent value of dynamic capabilities for competitive advantage: The nonlinear moderating effect of environmental dynamism. Strategic Management Journal 35: 179-203.

Schreyögg, G., and M. Kliesch-Eberl. 2007. How dynamic can organizational capabilities be? Towards a dual-process model of capability dynamization. Strategic Management Journal 28: 913-933.

Schumpeter, J.A. 1934. The theory of economic development: An inquiry into profits, capital, credit, interest, and the business cycle. Cambridge: Harvard University Press.

Sirmon, D.G., S. Gove, and M.A. Hitt. 2008. Resource management in dyadic competitive rivalry. Academy of Management Journal 51: 919-935.

Sirmon, D.G., M.A. Hitt, and R.D. Ireland. 2007. Managing firm resources in dynamic environments to create value: Looking inside the black box. Academy of Management Review 32: 273-292.

Sirmon, D.G., M.A. Hitt, R.D. Ireland, and B.A. Gilbert. 2011. Resource orchestration to create competitive advantage: Breadth, depth, and life cycle effects. Journal of Management 37: 1390-1412.

Smith, K.G., C.J. Collins, and K.D. Clark. 2005. Existing knowledge, knowledge creation capability, and the rate of new product introduction in high-technology firms. Academy of Management Journal 48: 346-357.

Spender, J.C. 1996. Making knowledge the basis of a dynamic theory of the firm. Strategic Management Journal 17:45-62.

Spender, J.C. 2008. Organizational learning and knowledge management. Management Learning 39: $159-176$.

Tanriverdi, H. 2005. Information technology relatedness, knowledge management capability, and performance of multi-business firms. MIS Quarterly 29: 311-334.

Teece, D.J. 1998. Capturing value from knowledge assets: The new economy, markets for know-how, and intangible assets. California Management Review 40: 55-79.

Teece, D.J., G. Pisano, and A. Shuen. 1997. Dynamic capabilities and strategic management. Strategic Management Journal 18: 509-533.

Tellis, G.J., J.C. Prabhu, and R.K. Chandy. 2009. Radical innovation across nations: The preeminence of corporate culture. Journal of Marketing 73: 3-23.

Terziovski, M. 2010. Innovation practice and its performance implications in small and medium enterprises (SMEs) in the manufacturing sector: A resource-based view. Strategic Management Journal 31: 892-902.

Tortoriello, M. 2015. The social underpinnings of absorptive capacity: The moderating effects of structural holes on innovation generation based on external knowledge. Strategic Management Journal 36: 586-597. 
Tsoukas, H., and N. Mylonopoulos. 2004. Organizational as knowledge systems: Knowledge, learning and dynamic capabilities. Basingstoke: Palgrave Macmillan.

Van Wijk, R., J.J. Jansen, and M.A. Lyles. 2008. Inter-and intra-organizational knowledge transfer: A meta-analytic review and assessment of its antecedents and consequences. Journal of Management Studies 45: 830-853.

Venkatraman, N., and V. Ramanujam. 1987. Measurement of business economic performance: An examination of method convergence. Journal of Management 13: 109-122.

Wang, C.L., and M. Rafiq. 2014. Ambidextrous organizational culture, contextual ambidexterity and new product Innovation: A comparative study of UK and Chinese high-tech firms. British Journal of Management 25: 58-76.

Wei, Z., Y. Yi, and H. Guo. 2014. Organizational learning, ambidexterity, strategic flexibility, and new product development. Journal of Product Innovation Management 31: 832-847.

Weitzman, M.L. 1998. Recombinant growth. Quarterly Journal of Economics 113: 331-360.

Wu, I.L., and J.L. Chen. 2014. Knowledge management driven firm performance: The roles of business process capabilities and organizational learning. Journal of Knowledge Management 18: $1141-1164$.

Yayavaram, S., and W.R. Chen. 2015. Changes in firm knowledge couplings and firm innovation performance: The moderating role of technological complexity. Strategic Management Journal 36: 377-396.

Zahra, S.A., and G. George. 2002. Absorptive capacity: A review, re-conceptualization, and extension. Academy of Management Review 27: 185-203.

Zahra, S.A., H.J. Sapienza, and P. Davidsson. 2006. Entrepreneurship and dynamic capabilities: A review, model and research agenda. Journal of Management Studies 43: 917-955.

Zhao, Y., Y. Lu, and X. Wang. 2013. Organizational unlearning and organizational relearning: A dynamic process of knowledge management. Journal of Knowledge Management 17: 902-912.

Zhou, K.Z., and F. Wu. 2010. Technological capability, strategic flexibility, and product innovation. Strategic Management Journal 31: 547-561. 